\title{
Некоммерческий сектор в период распространения новой коронавирусной инфекции: рестрикции и механизмы их преодоления
}

\author{
К. Е. Косыгина ${ }^{1 凶}$ \\ ${ }^{1}$ Вологодский научный центр Российской академии наук, ул. Горького, д. 56-а, \\ 160014, Вологда, Вологодская область, Российская Федерация
}

Для цитирования: Косыгина К. Е. Некоммерческий сектор в период распространения новой коронавирусной инфекции: рестрикции и механизмы их преодоления // Вестник Воронежского государственного университета. Серия: Экономика и управление. 2021. №. 2. С. 27-39. DOI: https://doi.org/10.17308/econ.2021.2/3461

\begin{abstract}
Предмет. Пандемия COVID-19 стала испытанием не только для систем здравоохранения, повседневной жизни людей, организации также столкнулись с новыми рисками и ограничениями, влияющими на их устойчивое функционирование и дальнейшее развитие. В настоящем исследовании рассматривается состояние организаций российского некоммерческого сектора в период распространения новой коронавирусной инфекции.
\end{abstract}

Цель. Идентификация и анализ рестрикций для развития организаций некоммерческого сектора и различных механизмов их преодоления в период введения целого ряда ограничений, вызванных распространением новой коронавирусной инфекции.

Материалы и методы. Информационной базой исследования послужили статистические материалы, аналитические и отчетные документы негосударственных и государственных структур, а также результаты, полученные отечественными и зарубежными исследователями по данной проблематике. Применяются методы: вторичного анализа социологических опросов; контентанализа официальных документов; систематизации и обобщения полученных данных.

Выводы. Проведенный анализ показал, что российские некоммерческие организации в условиях распространения коронавирусной инфекции оказались в сложной ситуации, как и другие хозяйствующие субъекты экономики. Выявлены основные ограничения функционирования сектора, к которым относятся финансовые и организационные. Систематизированы меры государственной поддержки некоммерческих организаций в единый организационно-экономический механизм и проанализированы отдельные количественные показатели: льготные кредиты, субсидии на мероприятия по профилактике коронавирусной инфекции, освобождение от уплаты авансовых платежей и страховых взносов, результаты специального внеочередного конкурса Фонда президентских грантов по развитию гражданского общества. Анализ количественных показателей свидетельствует о востребованности государственных антикризисных мер со стороны организаций некоммерческого сектора. Установлено, что совместно с государственными мерами преодоления трудностей, связанных с ограничительными мероприятиями, создан и частный организационно-экономический механизм поддержки некоммерческих организаций за счет ресурсов бизнеса, который рассмотрен в исследовании на примере деятельности благотворительных фондов. В заключении отмечено, что пандемия COVID-19 усилила развитие межсекторного взаимодействия при решении общих проблем. Опора на консолидацию и партнерство в сложных экономических условиях позволит некоммерческим организациям расширить и выбрать наиболее подходящие способы поддержания своей деятельности.

Ключевые слова: ограничения, некоммерческий сектор, COHKO, пандемия, COVID-19, государственная поддержка.

\section{Введение}

В экономической и политической науке используется термин «рестрикция» (с лат. restrictio - ограничение). В период распространения новой коронавирусной инфекции данное понятие приобрело особое значение и актуальность (см., например работы А. А. Шабуновой [19], Ю. Е. Шматовой [20]). Ограничения и карантин-

(c) Косыгина К. Е., 2021

Вестник ВГУ. Серия: Экономика и управление. 2021. № 2. С. 27-39. 
ные меры стали вводится в начале 2020 г., а уже весной Всемирная организация здравоохранения охарактеризовала ситуацию с новой коронавирусной инфекцией как пандемию, которая вмешалась в привычный ритм жизни во многих странах, внесла значительные коррективы в представление людей о своей безопасности в плане сохранения здоровья и самой жизни. Распространение COVID-19 радикально изменило социальную и экономическую реальность мировой цивилизации и российского общества. Пандемия серьезно повлияла не только на систему здравоохранения, повседневную жизнь людей, организации также столкнулись с новыми рисками и ограничениями, влияющими на их развитие и устойчивое функционирование. Очевидно, что преодоление эпидемиологического кризиса является ключевым условием для возвращения к нормальной жизни. Г. В. Осипова и др. [15] отмечают, что управленческой командой страны были приняты важные решения, которые во многом способствовали ограничению отрицательного воздействия пандемии. Одним из таких решений стало введение ограничительных мер, временное прекращение работы организаций и перевод сотрудников на удаленную работу. С. П. Земцов и Ю. В. Царева [9] констатируют, что пандемия COVID-19 внесла свои коррективы в деятельность субъектов малого и среднего предпринимательства. Исследование Е. М. Ануфриевой [7] показало, что некоммерческие негосударственные организации (далее - HКО) также оказались в сложном положении. Donthu and Gustafsson [3] отметили, что некоторые организации не успели перейти на онлайн-формат предоставления товаров и услуг, а те, чья модель деятельности завязана исключительно на очном предоставлении социальных услуг, были подвержены высокому риску ликвидации. Следовательно, поддержка организаций некоммерческого сектора как со стороны государства, так и со стороны иных экономических агентов выступает приоритетной задачей для достижения устойчивости их функционирования в кризисных условиях. Такая постановка проблемы, по мнению Casey [1], аргументируется значимой ролью НКО в экономическом и социальном развитии, что подтверждается исследованиями российских и зарубежных авторов.

Говоря об актуальности рассматриваемой проблематики, Corsini and Moultrie [2] отмечают, что некоторые из наиболее уязвимых групп населения зависят от НКО в период пандемии больше, чем когда-либо. Это люди с ограничен- ными возможностями здоровья, дети, бездомные, пожилые и другие группы, нуждающиеся в помощи. НКО в период ограничительных мер обеспечивали уязвимые категории граждан продуктами питания, товарами первой необходимости и средствами защиты, осуществляли поддержку учреждений здравоохранения и медицинских работников, оказывали психологическую и юридическую помощь.

Целью настоящего исследования является описание рестрикций (ограничений) развития организаций российского некоммерческого сектора и механизмов их преодоления в период распространения новой коронавирусной инфекции. Исходя из цели, можно сформулировать ряд исследовательских задач: определение категорий НКО, наиболее подверженных воздействию пандемии COVID-19; изучение ограничений и барьеров их деятельности; анализ механизмов поддержки НКО.

\section{Материалы и методы исследования}

Проблемы адаптации организаций некоммерческого сектора к условиям пандемии COVID-19 отражены в информационно-аналитических материалах крупных исследовательских государственных учреждений и негосударственных структур, что доказывает востребованность предмета исследования со стороны научного сообщества и практиков. Авторы Центра оценки общественных инициатив Института прикладных политических исследований НИУ ВШЭ проанализировали зарубежный опыт поддержки НКО во время пандемии ${ }^{1}$ и описали российские социальные практики помощи НКО уязвимым группам населения ${ }^{2}$. Сотрудники Центра исследований гражданского общества и некоммерческого сектора НИУ ВШЭ представили данные о самоорганизации граждан и жизнестойкости $\mathrm{HKO}^{3}$. Благотворительный фонд развития филантропии «КАФ» (далее - БФ «КАФ») провёл две волны социологических исследований, посвященных послед-

1 «Поддержка НКО во время пандемии: зарубежный опыт». Центр оценки общественных инициатив Института прикладных политических исследований НИУ ВШЭ. URL: https://politinst.hse.ru.

2 «Вклад НКО в борьбу с пандемией: российский контекст». Центр оценки общественных инициатив Института прикладных политических исследований НИУ ВШЭ. URL: https://politinst.hse.ru.

3 «Самоорганизация граждан. Жизнестойкость НКО во время пандемии». Центр исследований гражданского общества и некоммерческого сектора НИУ ВШЭ. URL: https://www.hse.ru/data/2020/07/28/1598473677/HSE_ Covid_10_2020_4_1.pdf. 
Некоммерческий сектор в период распространения новой коронавирусной инфекции...

ствиям пандемии коронавируса для НКО: в первой волне выборка составила 232 организации из 48 регионов (замеры проводились в марте 2020 г. $)^{4}$, во второй - 194 организации из 45 регионов (замеры проводились в июне 2020 г. $)^{5}$. В Докладе о состоянии гражданского общества в РФ за 2020 г. также один из разделов посвящен работе некоммерческих организаций во время распространения коронавирусной инфекции. Интерес представляет исследование В. Ю. Кульковой [14], в фокусе внимания которой - государственная поддержка некоммерческих организаций сферы услуг в условиях кризиса 2020 г. Автор применяет метод экспертных оценок.

Настоящая работа во многом опирается на перечисленные исследования, используемые в качестве информационной базы. Применяются методы вторичного анализа социологических опросов без проведения собственных полевых исследований и экспериментов. Кроме того, используются контент-анализ официальных документов и анализ статистических данных.

Фактически спектр исследований и публикаций по рассматриваемой теме ограничен, поскольку COVID-19 является новым вызовом для общества и еще не завершившимся. Научный дискурс только утверждается и идет формирование общего набора проблем, требующих научно обоснованных решений. Поэтому обращение к вопросу функционирования организаций некоммерческого сектора в период распространения новой коронавирусной инфекции является востребованным направлением исследования, а разработанный дизайн исследования и обобщающие, аналитические выводы обладают элементами научной новизны.

\section{Обсуждение результатов}

1. Определение категорий НКО, наиболее подверженных воздействию ограничительных мер пандемии COVID-19, и выявление барьеров их деятельности в сложившихся условиях

В начале 2020 г. Общественной палатой РФ были организованы общественные слушания и горячая линия по проблеме поддержки НКО в условиях пандемии. На основе обобщения этих двух источников информации была опубликована итоговая резолюция, в которой выделены две категории НКО, наиболее подверженные воздействию пандемии новой коронавирусной инфекции ${ }^{6}$.

Первую категорию составляют социально ориентированные НКО (далее - СОНКО), оказывающие населению услуги в социальной сфере. Статистические данные показывают рост числа получателей услуг СОНКО в допандемийный период с 2017 по 2019 г., что свидетельствует о качественном и количественном развитии сектора, увеличении спроса на подобные услуги (табл. 1).

Однако пандемия COVID-19 внесла коррективы. СОНКО стали уязвимы под влиянием необходимых ограничительных мер, призванных остановить распространение вируса (март-апрель 2020 г.). В условиях ограничений и самоизоляции возникли существенные барьеры организационно-административного характера в деятельности некоммерческого сектора. Распределение ответов на вопрос «С какими трудностями вы сталкиваетесь в адаптации к

Т а бл иц а 1

Количество потребителей услуг СОНКО на 1000 человек

\begin{tabular}{|l|c|c|}
\hline \multirow{2}{*}{ Сфера } & \multicolumn{2}{|c|}{ Год } \\
\cline { 2 - 3 } & 2017 & 2019 \\
\hline Образование & 60,1 & 124,5 \\
\hline Здравоохранение & 84,7 & 106,5 \\
\hline Социальная политика & 43,8 & 59,2 \\
\hline Культура & 63,9 & 114,1 \\
\hline Спорт & 33,7 & 47,4 \\
\hline Получателей услуг, всего & 286,2 & 451,7 \\
\hline
\end{tabular}

И с т о ч н и к д а н н ы х: рассчитано автором по данным ЕМИСС «Количество человек, которым оказаны социальные услуги с 2017 года». URL: https://fedstat.ru/indicator/58621.

${ }^{4}$ Новая реальность. Как COVID-19 меняет работу российских НКО, 2020. URL: http://cafrussia.ru/storage/ files/file-114.pdf.

${ }^{5}$ НКО и коронавирус: Остаться в живых, июнь 2020. URL: http://cafrussia.ru/storage/files/file-111.pdf.
${ }^{6}$ Резолюция Общественной палаты Российской Федерации по итогам общественных слушаний на тему: «Меры поддержки НКО в условиях пандемии». URL: https://www.oprf.ru/ru/about/structure/structurenews/ newsitem/53098. 
нынешним условиям?» показывает, что основной проблемой для НКО стало приспособление программ и проектов к онлайн-формату, такое мнение высказали 35 \% респондентов. Отсутствие технической инфраструктуры для полноценной удаленной работы отметили 26 \%, при этом никогда не приходилось работать в дистанционном режиме $19 \%$ опрошенных организаций. Выразили беспокойство о том, что благополучатели не готовы к взаимодействию в виртуальном пространстве, 23 \% (табл. 2).

Кроме того, дистанционный формат работы оказал влияние на взаимоотношения с заказчиками и донорами. Так, в случае перевода услуги в онлайн, некоммерческие организации сталкиваются с трудностями предоставления отчетности об исполнении договора или государственного контракта. Отсутствие опыта работы в удаленном режиме порождает проблемы управления и организации деятельности, а также дополнительные издержки на приобретение оборудования.

Таким образом, переход на удаленную работу и перевод в онлайн-сервисы социальных услуг оказались затруднительны в организационном плане, а в некоторых случаях стали невозможными. Потребители услуг СОНКО - прежде всего особые категории граждан (пенсионеры, инвалиды, дети и др.), которые находились на самоизоляции и не имели возможности получить необходимую помощь. Следовательно, деятельность приостановили образовательные организации, сферы культуры, спорта и т. д.

Тем не менее, как фиксируют замеры БФ «КАФ», уже к июню 2020 г. НКО адаптировались к новым условиям работы: $49 \%$ запустили новые программы, преимущественно в области поддержки людей по горячим линиям, доставки продовольственных и непродовольственных товаров для обеспечения жизнедеятельности, помощи медицинским организациям. Сократили свою программную деятельность только 15 \% опрошенных $\mathrm{HKO}^{7}$. Отсюда следует, что способность НКО адаптироваться к условиям пандемии и смена программ привели к противоположному положительному процессу - повышению спроса на услуги.

Вторую категорию наиболее пострадавших составляют благотворительные НКО, испытывающие сокращение объема пожертвований от граждан и организаций в период пандемии в связи с сокращением располагаемых доходов населения (см. Л. В. Камдина [10]) и прибыли бизнеса (см., напр.: С. П. Земцов, Ю. В. Царева [9]). Информация о структуре источников формирования денежных средств НКО до текущей эпидемии свидетельствует, что основной объем финансирования поступает от физических и юридических лиц (за 2019 г. более 40 \%). При этом пожертвования от бизнеса снизились с 2017 по 2019 г. поступления от населения, напротив, незначительно увеличились (табл. 3).

При отсутствии данных официальной статистики за 2020 г. оценка объема пожертвований возможна с учетом материалов опросов. Большинство представителей некоммерческих организаций (60 \%), ранее получавших благотворительную помощь, отмечают, что в период пандемии COVID-19 поступления значительно сократились. Объём пожертвований упал в каждой пятой организации более чем на 80 \%. Причем региональные НКО получали меньше средств от населения и компаний, чем московские. Учитывая, что большую долю доходов HКО на осуществление программ, мероприятий, производство услуг занимают именно эти

Т а бли ц а 2

Распределение ответов на вопрос «С какими трудностями вы сталкиваетесь в адаптации к нынешним условиям?» (N=232 НКО, первая волна, март 2020 г.)

\begin{tabular}{|l|c|}
\hline \multicolumn{1}{|c|}{ Варианты ответа } & $\%$ \\
\hline Наши программы и проекты плохо ложатся в онлайн-формат & 35 \\
\hline Наша техническая инфраструктура не позволяет полноценно работать удаленно & 26 \\
\hline У нас нет никаких трудностей & 26 \\
\hline Наши благополучатели не готовы взаимодействовать с нами в онлайн-формате & 23 \\
\hline Нам никогда не приходилось работать в удаленном режиме & 19 \\
\hline Другое & 14 \\
\hline
\end{tabular}

И с т о ч н и к д а н н ы х: результаты первой волны (март 2020 г.) социологического исследования БФ «KAФ». URL: http://cafrussia.ru/storage/files/file-114.pdf.

${ }^{7}$ Исследование БФ «КАФ». «НКО и коронавирус: остаться в живых». URL: http://cafrussia.ru/storage/files/ file-111.pdf. 
Некоммерческий сектор в период распространения новой коронавирусной инфекции...

Т а бл и ц а 3

Источники формирования денежных средств СОНКО, в \% к общему количеству поступлений

\begin{tabular}{|l|c|c|}
\multicolumn{1}{|c|}{\begin{tabular}{l} 
Источники формирования денежных средств \\
\multicolumn{1}{|c|}{ и иного имущества организаций }
\end{tabular}} & 2017 & 2019 \\
\hline Всего поступило & 100,0 & 100,0 \\
\hline \multicolumn{1}{|c|}{ в том числе } & 5,5 & 7,1 \\
\hline из федерального бюджета & 4,6 & 5,1 \\
\hline из бюджетов субъектов Российской Федерации & 0,8 & 1,1 \\
\hline из муниципальных (местных) бюджетов & 0,7 & 0,8 \\
\hline из бюджетов государственных внебюджетных фондов & 13,4 & 14,2 \\
\hline от физических лиц & 11,1 & 8,1 \\
\hline от некоммерческих организаций & 23,5 & 18,5 \\
\hline от коммерческих организаций & 1,9 \\
\hline $\begin{array}{l}\text { от иностранных государств, их государственных органов, международных } \\
\text { и иностранных организаций }\end{array}$ & 2,3 \\
\hline от иностранных граждан и лиц без гражданства & 0,1 & 0,5 \\
\hline доход от целевого капитала & 0,2 & 0,3 \\
\hline доход от продажи товаров, работ, услуг & 30,9 & 34,1 \\
\hline внереализационные доходы & 2,4 & 3,0 \\
\hline $\begin{array}{l}\text { денежные средства и иное имущество, полученное безвозмездно от хозяйствен- } \\
\text { ных обществ, учрежденных организацией }\end{array}$ & 0,3 & 0,8 \\
\hline иные поступления & 4,6 & 4,1 \\
\hline
\end{tabular}

И с т о ч н и к д а н н ы х: итоги выборочного обследования социально ориентированных некоммерческих организаций за 2017, 2019 годы на основе формы № 1 - COHKO. URL: https://rosstat.gov.ru/folder/11191.

поступления, то их сокращение введет к потере финансовой устойчивости, которая в свою очередь является ключевым элементом эффективности деятельности. Данные утверждения согласуются с результатами Goodell et al. [4] и И. Е. Корнеевой [11].

Сокращение объема пожертвований от населения и бизнеса, приостановление оказания социальных услуг, неисполнение условий ранее заключенных договоров привело к отсутствию средств на выплату заработной платы, оплату страховых взносов и налогов, арендных и коммунальных платежей. Так, по данным БФ «КАФ», 63 \% опрошенных организаций не сократили штат сотрудников и их заработную плату, 22 \% урезали заработную плату работникам, а 7 \% отметили, что им пришлось уволить часть сотрудников.

Проведенный анализ показал, что российские НКО в условиях распространения коронавирусной инфекции оказались в трудной ситуации, как и другие хозяйствующие субъекты. Выявлены основные ограничения в функционировании организаций сектора финансового и организационного характера, которые могли повлечь значительное сокращение или полное прекращение их работы. Подчеркнем, что на момент проведения исследования отсутство- вала информация Росстата об итогах обследования СОНКО за 2020 г., поэтому количественные показатели деятельности сектора не представлены в полном объеме. Вместе с тем данные опросов дают основание сформировать и понять ключевые тренды и проблемы развития российского некоммерческого сектора в кризисных условиях.

2. Механизмы поддержки НКО во время распространения новой коронавирусной инфекции

Обеспечение жизнестойкости НКО во время распространения новой коронавирусной инфекции является сложным процессом, который требует комплексного и системного подхода к его реализации. Согласно результатам А. Е. Кремина [13], здесь применимо формирование организационно-экономического механизма (далее - ОЭМ), позволяющего достигать поставленной цели с учетом тенденций развития и текущего состояния исследуемого сектора экономики. В исследовании за основу возьмем определение ОЭМ, данное Ф. Х. Цхурбаевой, И. Т. Фарниевой: «ОЭМ - совокупность организационных и экономических средств воздействия субъекта управления на управляемый объект с целью достижения желательных состояний объекта управления посредством 
выработки управленческих решений, обеспечивающих соединение статики и динамики» [18, с. 153]. В нашем случае субъектом выступают органы государственной власти федерального уровня, а объектом - НКО.

В целях нивелирования выявленных проблем, которые возникли в период пандемии у некоммерческого сектора, государство предложило и утвердило ряд антикризисных мер финансово-экономического, имущественного и организационно-административного характера. Анализ и систематизация данных мер позволила объединить их в единый организационно-экономический механизм государственной поддержки НКО в условиях распространением новой коронавирусной инфекции (рис. 1).
ОЭМ государственной поддержки некоммерческих организаций в условиях COVID-19 находит отражение в количественных показателях. В частности, самой востребованной мерой среди СОНКО выступило освобождение государственных внебюджетных фондов от уплаты страховых взносов: воспользовались - 24,2 тыс. организаций на общую сумму 8,8 млрд руб. Пользовались спросом и послабления по уплате авансовых платежей: было распределено 162 млн руб., а обратились за помощью более 1 тыс. СОНКО. В период пандемии некоммерческий сектор активно подключился к борьбе с проявлениями и последствиями инфекции, поэтому государством было принято решение о предоставлении субсидий на мероприятия по профилактике коронавирусной инфекции. С одной стороны, неком-
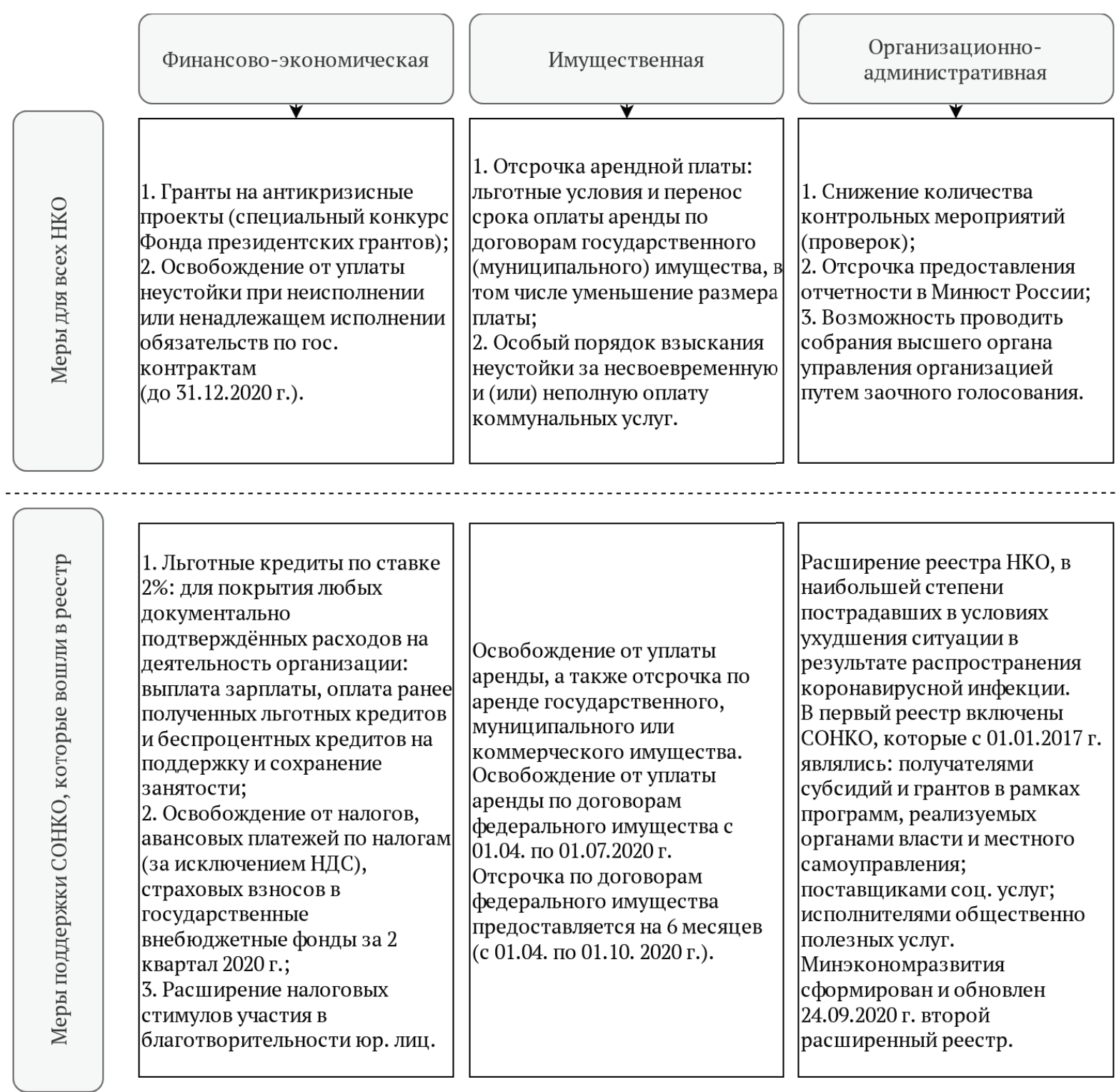

\begin{tabular}{|l|}
\hline \\
Освобождение от уплаты \\
аренды, а также отсрочка по \\
аренде государственного, \\
муниципального или \\
коммерческого имущества. \\
Освобождение от уплаты \\
аренды по договорам \\
федерального имущества с \\
01.04. по 01.07.2020 г. \\
Отсрочка по договорам \\
федерального имущества \\
предоставляется на 6 месяцев \\
(с 01.04. по 01.10. 2020 г.). \\
\\
\end{tabular}

\begin{tabular}{|l|}
\hline Расширение реестра НКО, в \\
наибольшей степени \\
пострадавших в условиях \\
ухудшения ситуации в \\
результате распространения \\
коронавирусной инфекции. \\
В первый реестр включены \\
СОНКО, которые с 01.01.2017 г. \\
являлись: получателями \\
субсидий и грантов в рамках \\
программ, реализуемых \\
органами власти и местного \\
самоуправления; \\
поставщиками соц. услуг; \\
исполнителями общественно \\
полезных услуг. \\
Минэкономразвития \\
сформирован и обновлен \\
24.09 .2020 г. второй \\
расширенный реестр. \\
\hline
\end{tabular}

Puc. 1. Организационно-экономический механизм государственной поддержки НКО в условиях распространением новой коронавирусной инфекции (составлено автором) 
Некоммерческий сектор в период распространения новой коронавирусной инфекции...

Т а бл и ц а 4

Количественные показатели государственной поддержки некоммерческого сектора в период распространения новой коронавирусной инфекции, 2020 г.

\begin{tabular}{|l|c|c|}
\hline \multicolumn{1}{|c|}{ Мера поддержки } & $\begin{array}{c}\text { Количество СОНКО - } \\
\text { получателей государст- } \\
\text { венной поддержки, ед. }\end{array}$ & $\begin{array}{c}\text { Объем распреде- } \\
\text { ленных денежных } \\
\text { средств, млн руб. }\end{array}$ \\
\hline $\begin{array}{l}\text { Льготные кредиты на возобновление } \\
\text { деятельности организаций }\end{array}$ & 1008 & 2744,6 \\
\hline $\begin{array}{l}\text { Субсидии на мероприятия по профилактике корона- } \\
\text { вирусной инфекции }\end{array}$ & 4180 & 930,8 \\
\hline Освобождение от уплаты авансовых платежей & 1742 & 162,0 \\
\hline Освобождение от уплаты страховых взносов & 24200 & 8000,8 \\
\hline Специальный внеочередной конкурс ФПг & 900 & 2000,0 \\
\hline Всего получателей & 32030 & 13838,2 \\
\hline
\end{tabular}

И с т о ч н и к д а н н ы х: доклад о состоянии гражданского общества в Российской Федерации за 2020 г. М. : Общественная палата Российской Федерации, 2020.

мерческие организации играют существенную роль, их помощь может сохранить здоровье, а порой и спасти жизнь тех, кому они призваны помогать. С другой стороны, при непосредственном проведении мероприятий решаются экономические проблемы занятости, которые обострились во время пандемии: НКО привлекалась дополнительная рабочая сила, создавались рабочие места, выплачивалась заработная плата. Общая сумма субсидий на мероприятия составила 931 млн руб., получили ее более 4 тыс. организаций. Еще одной существенной мерой государственной поддержки стало проведение специального внеочередного конкурса Фонда президентских грантов (далее - ФПГ). Победители распределили между собой 2 млрд руб. (табл. 4).

Необходимо сосредоточить внимание на формальных моментах специального внеочередного конкурса. В основных ежегодных конкурсах проектов утверждаются 16 направлений, по которым предоставляется грант. В специальном конкурсе проекты поддерживаются по трем направлениям, наиболее значимым в период пандемии. В их число входят: социальное обслуживание, социальная поддержка и защита граждан; охрана здоровья граждан, пропаганда здорового образа жизни; поддержка семьи, материнства, отцовства и детства. Положением оговариваются основные группы благополучателей: наиболее подверженные негативному воздействию коронавирусной инфекции и непосредственно работающие с заразившимися ${ }^{8}$.

8 Положение о специальном конкурсе на предоставление грантов Президента Российской Федерации на развитие гражданского общества. URL: https:/президенскиегранты.pф/public/home/documents.
Информационная система ФПГ позволяет оценить распределение финансирования поддержанных проектов некоммерческих организаций в региональном разрезе. Рассмотрим на примере трех регионов СЗФО, отличающихся разным уровнем развития некоммерческого сектора. Информация свидетельствует, что Вологодская область является самым активным регионом из представленных и участвующих в конкурсе: поддержано 18 проектов на сумму 36,9 млн руб. Напротив, Республика Карелия выступает наименее активным участником: поддержано всего 5 проектов на сумму 5 млн руб. (табл. 5).

Наблюдается дифференциация регионов по поддержке проектов в рамках специального внеочередного конкурса ФПГ. Причины такой тенденции кроются не в предпочтениях государства, а в инициативности самих некоммерческих организаций, в качестве подготовленных заявок и т. д. Безусловно, оказанная НКО поддержка в рамках организованного конкурса положительно скажется на устойчивости и жизнестойкости рассматриваемых организаций во время пандемии COVID-19.

В ответ на кризис, вызванный новой коронавирусной инфекцией, бизнес предложил поддержку некоммерческим организациям. В частности, откликнулись благотворительные фонды при крупных коммерческих компаниях. В исследование включены два фонда - Владимира Потанина, Елены и Геннадия Тимченко. Следует отметить, что в рейтинге российских благотворительных фондов Forbes за 2019 г. занимают первое и второе места. Выбор этих фондов также обусловлен длительностью их 
Распределение финансирования проектов некоммерческих организаций, поддержанных Фондом президентских грантов в рамках специального внеочередного конкурса в период борьбы с распространением новой коронавирусной инфекции, 20202.

\begin{tabular}{|c|c|c|}
\hline Грантовое направление & $\begin{array}{c}\text { Кол-во под- } \\
\text { держанных } \\
\text { проектов, ед. }\end{array}$ & $\begin{array}{l}\text { Сумма*, } \\
\text { млн руб. }\end{array}$ \\
\hline \multicolumn{3}{|l|}{ Вологодская область } \\
\hline Поддержка семьи, материнства, отцовства и детства & 5 & 16,7 \\
\hline Социальное обслуживание, социальная поддержка и защита граждан & 11 & 15,6 \\
\hline Охрана здоровья граждан, пропаганда здорового образа жизни & 2 & 4,6 \\
\hline Всего по грантовым направлениям & 18 & 36,9 \\
\hline \multicolumn{3}{|l|}{ Псковская область } \\
\hline Социальное обслуживание, социальная поддержка и защита граждан & 3 & 10,3 \\
\hline Всего по грантовым направлениям & 3 & 10,3 \\
\hline \multicolumn{3}{|l|}{ Калининградская область } \\
\hline Социальное обслуживание, социальная поддержка и защита граждан & 8 & 17,3 \\
\hline Охрана здоровья граждан, пропаганда здорового образа жизни & 4 & 2,0 \\
\hline Поддержка семьи, материнства, отцовства и детства & 1 & 3,0 \\
\hline Всего по грантовым направлениям & 13 & 22,3 \\
\hline \multicolumn{3}{|l|}{ Республика Карелия } \\
\hline Поддержка семьи, материнства, отцовства и детства & 3 & 4,1 \\
\hline Охрана здоровья граждан, пропаганда здорового образа жизни & 2 & 0,9 \\
\hline Всего по грантовым направлениям & 5 & 5,0 \\
\hline
\end{tabular}

И с т о ч н и к д а н н ы х: официальный сайт Фонда президентских грантов.

* С учетом софинансирования.

функционирования. В целом это особый тип некоммерческих организаций, создаваемых крупными корпорациями для решения социальных задач. Данные структуры финансируются из средств компании, с которой они ассоциированы, или за счет собственных средств создателей, добровольных взносов, а также дивидендов. Деятельность благотворительных фондов связана с предоставлением грантов на реализацию проектов, направленных на решение или смягчение существующих социальных проблем. Как показано в работе К. Е. Косыгиной [12, с. 61], в грантовых конкурсах участвуют преимущественно некоммерческие организации, хотя некоторые фонды предоставляют возможность реализовывать свои проекты инициативным гражданам без образования юридического лица.

Изучив и обобщив информацию с официальных сайтов рассматриваемых благотворительных фондов, их меры поддержки НКО, можно сформировать частный организационно-экономический механизм поддержки НКО в период пандемии COVID-19, который перекликается с государственным, так как обеспечивает такие же антикризисные меры: финансово- экономические, организационно-административные и имущественные (рис. 2).

Распределение объема денежных средств, направленных на борьбу с пандемией, в том числе на поддержку НКО, работающих с уязвимыми группами граждан, показывает, что суммарно направлено более 4 млрд руб. Благотворительный фонд Елены и Геннадия Тимченко выделил 2,9 млрд руб. (табл. 6). А объем расходов фонда В. Потанина в 2020 г. увеличился на $82 \%$ в связи с антикризисными инициативами 9 .

Детализация направлений финансирования благотворительного фонда В. Потанина на поддержку НКО и инициативных групп граждан в период пандемии показывает, что средства в первую очередь выделялись на сохранение организационной устойчивости организаций: поддержку уставной деятельности, обучение работе в удаленном режиме, поддержку текущих грантополучателей (табл. 7).

Таким образом, пандемия COVID-19 потребовала мобилизации ресурсов трех секторов некоммерческого, бизнеса и государства. Вызов современному обществу в лице коронавирусной

9 Официальный сайт благотворительного фонда В. Потанина. URL: https://www.fondpotanin.ru/. 
Некоммерческий сектор в период распространения новой коронавирусной инфекции...
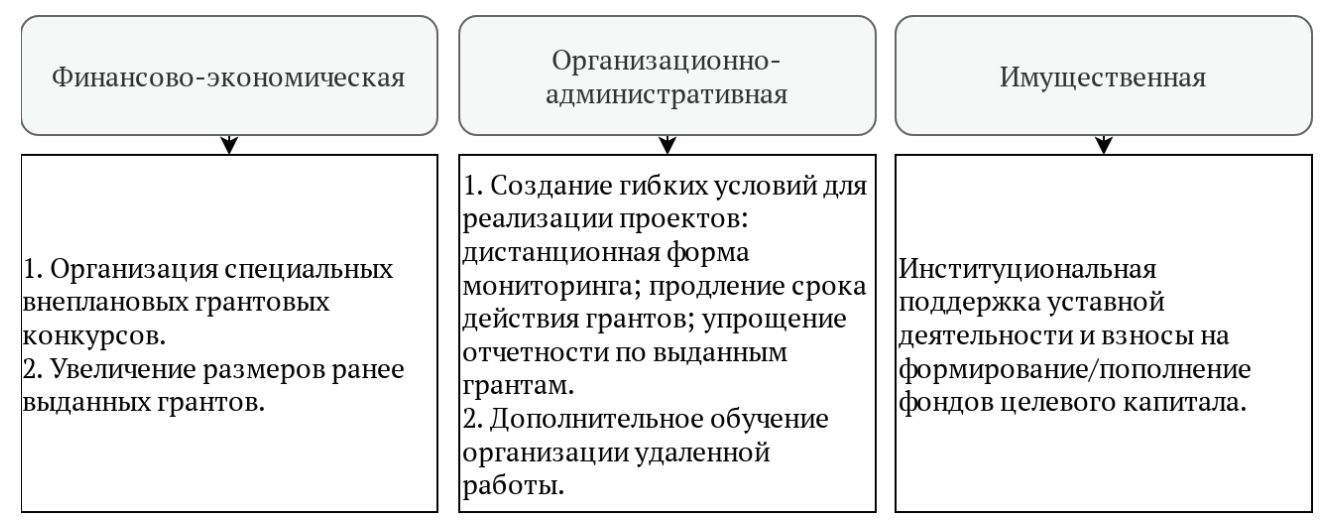

Puc. 2. Частный организационно-экономический механизм поддержки НКО в период пандемии (на примере деятельности благотворительных фондов) (составлено автором)

Т а бл и ц а 6

Объем денежных средств, направленных на борьбу с пандемией, в том числе на поддержку НКО, работающих с уязвимыми группами граждан

\begin{tabular}{|l|c|}
\hline \multicolumn{1}{|c|}{ Наименование фонда } & Объем денежных средств, млрд руб. \\
\hline Благотворительный фонд В. Потанина & 1,36 \\
\hline Благотворительный фонд Елены и Геннадия Тимченко & 2,90 \\
\hline
\end{tabular}

И с т о ч н и к д а н н ы х: официальные сайты благотворительного фонда В. Потанина. URL: https://www. fondpotanin.ru/; благотворительного фонда Елены и Геннадия Тимченко.URL: http://timchenkofoundation.org/.

Т а б ли ц а 7

Направления финансирования благотворительного фонда В. Потанина

на поддержку НКО и инициативных групп граждан в период пандемии

\begin{tabular}{|l|c|}
\hline \multicolumn{1}{|c|}{ Краткая характеристика / основное направление поддержки } & Название конкурса / программы \\
\hline $\begin{array}{l}\text { Поддержка уставной деятельности, формирование целевого } \\
\text { капитала социальных инфраструктурных организаций, которые } \\
\text { работают в период пандемии в сферах риска и с наиболее уязви- } \\
\text { мыми группами людей }\end{array}$ & «Новое измерение» \\
\hline $\begin{array}{l}\text { Предоставление на конкурсной основе финансирования ини- } \\
\text { циативным группам и НкО на проекты по улучшениюусловий } \\
\text { жизни уязвимых слоев населения (своих благополучателей) }\end{array}$ & «Школа филантропии» \\
\hline $\begin{array}{l}\text { Адаптация деятельности НКО к работе в удаленном режиме, } \\
\text { обучение, информационно-консультативная поддержка }\end{array}$ & \multicolumn{1}{|c|}{ «Общее дело» } \\
\hline $\begin{array}{l}\text { Поддержка текущих грантополучателей (увеличение суммы } \\
\text { грантов на } 10 \%)\end{array}$ & \\
\hline
\end{tabular}

И с т о ч н и к д а н н ы х: официальный сайт благотворительного фонда В. Потанина. URL: https://www. fondpotanin.ru/

инфекции подтолкнул к развитию межсекторного взаимодействия, совместному решению социальных и экономических проблем. Механизмы взаимодействия организаций некоммерческого сектора как с бизнесом, так и с государством, созданные и апробированные в условиях пандемии, с большой долей вероятности найдут применение в дальнейшем и окажут положительное влияние на развитие сектора. В то же время расширение партнерства приводит к мобилизации ресурсов нескольких секторов общества и более эффективному развитию не только НКО, но и экономики страны в целом.

\section{Заключение}

Некоммерческие организации адаптируются к сложившимся условиям, им приходится преодолевать трудности, связанные с диверсификацией и ограничением финансирования, барьерами в коммуникации и другими проблемами, которые заслуживают их собственного внимания по мере того, как российское общество и экономика выходят из кризиса, вызванного распространением новой коронавирусной инфекции.

Проведенный анализ показал, что российские НКО, как и другие хозяйствующие субъекты, во время распространения коронавирусной 
инфекции столкнулись с рядом проблем в своей деятельности. К числу выявленных основных проблем и ограничений функционирования сектора можно отнести финансовые и организационные. Ограничения финансового характера в первую очередь связаны со спадом объема пожертвований от физических и юридических лиц. Организационного характера - с трудностями перехода в онлайн-формат работы с благополучателям и донорами.

В исследовании меры государственной поддержки НКО систематизированы в единый ОЭМ. Анализ количественных показателей свидетельствует о востребованности государственных антикризисных мер со стороны организаций некоммерческого сектора. Поддержку получили более 32 тыс. НКО на сумму более 13 млрд руб. Совместно с государственными мерами преодоления трудностей, связанных с ограничительными мероприятиями, сформирован и частный ОЭМ поддержки некоммерческих организаций за счет ресурсов бизнеса, который рассмотрен в исследовании на примере деятельности благотворительных фондов. Пандемия COVID-19 усилила развитие межсекторного взаимодействия при решении общих проблем. Опора на консолидацию и партнерство в сложных экономических условиях позволит некоммерческим организациям расширить и выбрать наиболее подходящие способы осуществеления своей деятельности. Внимание и поддержка государства и бизнеса обеспечат рост доверия к некоммерческому сектору со стороны населения,

\section{Библиографический список}

1. Casey J. The Nonprofit World - Civil Society and the Rise of the Nonprofit Sector. Boulder and London: Kumarian Press, 2015.

2. Corsini L., Moultrie J. Local and distributed manufacturing during the COVID-19 pandemic: Is crisis a window of opportunity for sustainable development in the Global South? // Strategic Design Research Journal. 2021. Vol. 14, no. 1.P. 224-235. DOI: 10.4013/sdrj.2021.141.19

3. Donthu N., Gustafsson A. Effects of COVID-19 on business and research // Journal of Business Research. 2020. Vol. 117. P. 284-289

4. Goodell J., Goyal A., Hasan I. Comparing financial transparency between for-profitand nonprofit suppliers of public goods: Evidence from microfinance// Journal of International Financial Markets, Institutions \& Money. 2020. Vol. 64. P. 101-146.

5. Salamon L., Anheier H., ListR., Toepler S., Sokolowski $S$. Global civil society. Baltimore: Johns Hopkins University, Center for Civil Society Studies, 1999. увеличат гражданскую активность и инициативность в решении актуальных задач.

В заключение важно отметить, что пандемия COVID-19 стала катализатором в осознании необходимости перемен, пересмотра стратегий, расстановки приоритетов. У НКО появилась возможности для перепроверки правильности выбора действий, разработки новых идей, что позволит ответить на вызовы времени и отсечь то, что невозможно или неэффективно реализовывать в краткосрочной и среднесрочной перспективе ${ }^{10}$.

Перспективным направлением исследований в русле данной проблематики является оценка эффективности действий государства, вводимых мер поддержки некоммерческого сектора с точки зрения самих организаций. В том числе видится необходимым определение новых форм конструктивного взаимодействия органов власти, бизнеса и организаций некоммерческого сектора в посткризисный период.

\section{Источник финансирования}

Исследование выполнено при финансовой поддержке РФФИ в рамках проекта 19-01100724 A «Барьеры гражданского участия и механизмы их преодоления на региональном уровне».

\section{Конфликт интересов}

Автор декларирует отсутствие явных и потенциальных конфликтов интересов, связанных с публикацией настоящей статьи.

6. Willems J., Boenigk S., Jegers M. Seven trade-offs in measuring nonprofit performance and effectiveness // Voluntas. 2014. Vol. 25 (6). P. 1648-1670.

7. Ануфриева Е. М. Особенности предоставления государственной помощи малому и среднему предпринимательству из пострадавших отраслей экономики в связи с пандемией COVID-19// Вестник Пензенского государственного университета. 2020. № 4 (32). 2020. C. 31-34.

8. Артамонова А. С. Роль некоммерческих организаций в социальной сфере региона (на примере здравоохранения) // Вестник Самарского государственного экономического университета. 2019. № 11 (181). C. 24-73.

9. Земцов С. П. Царева Ю. В. Тенденции развития сектора малых и средних предприятий в усло-

10 Жизнестойкость НКО во время пандемии. Центр исследований гражданского общества и некоммерческого сектора НИУ ВШЭ. URL: https://www.hse.ru/ data/2020/07/28/1598473677/HSE_Covid_10_2020_4_1.pdf. 
Некоммерческий сектор в период распространения новой коронавирусной инфекции...

виях пандемии и кризиса // Экономическое развитие России. 2020. № 5. С. 71-82.

10. Камдина Л. В. Оценка влияния пандемии covid-19 на качество жизни населения // Вестник Челябинского государственного университета. 2020. № 11 (445). С. 224-230.

11. Корнеева И. Е. Фандрайзинг в российских некоммерческих организациях: результаты эмпирического исследования // Мониторинг общественного мнения: Экономические и социальные перемены. 2016. № 4. С. 48-66.

12. Косыгина К. Е. Межсекторное взаимодействие: типы отношений и тенденции развития в современном российском обществе // Проблемы развития территории. 2020. № 6 (110). С. 50-66. DOI: 10.15838/ptd.2020.6.110.4 1.

13. Кремин A. Е. Управление экономикой региона на основе развития малого бизнеса: монография / под науч. рук. К.А. Гулина. Вологда : ФГБУН ВолНЦ РАН, 2019. 150 с.

14. Кулькова В. Ю. Некоммерческий сектор и государственная поддержка некоммерческих организаций сферы услуг в РФ в условиях кризиса 2020 г. // Государственное управление. Электронный вестник. 2020. № 80. С. 5-21.

15. Российское общество и государство в условиях пандемии: социально-политическое положе- ние и демографическое развитие Российской Федерации в 2020 году / Осипов Г. В. [и др.] ; под ред. Г. В. Осипова, С. В. Рязанцева, В. К. Левашова, Т. К. Ростовской ; отв. ред. В.К. Левашов. М. : Перспектива, 2020. 532 с.

16. Суслова С. В. Вклад российских некоммерческих организаций в национальную экономику // Финансы и бизнес. 2015. № 1. С. 75-87

17. Уханова Ю. В. Гражданское участие в российских регионах: сравнительный анализ // Вопросы территориального развития. 2019. № 5. URL: http://vtr.isert-ran.ru/article/28380 DOI: 10.15838/ tdi.2019.5.50.6

18. Цхурбаева Ф. Х., Фарниева И. Т. Организационно-экономический механизм управления предприятиями АПК // Terra Economicus. 2009. Т. 7, № 2-3. С. $151-154$.

19. Шабунова А. А. Здоровье и самосохранительное поведение населения в контексте COVID-19 // Социальное пространство. 2020. T. 6, № 3. URL: http://socialarea-journal.ru/article/28613

20. Шматова Ю. Е. Влияние COVID-19 на психическое здоровье населения (как показатель человеческого потенциала) : опыт зарубежных исследований // Проблемы развития территории. 2020. № 4 (108). C. 88-108. DOI: 10.15838/ptd.2020.4.108.6

Поступила в редакц̧ию 12.05.2021 Подписана в печать 17.06.2021 сотрудник лаборатории исследования социальных процессов и эффективности государственного управления отдела исследования уровня и образа жизни населения, Вологодский научный центр Российской академии наук, Вологда, Российская Федерация

E-mail: sene4ka.87@mail.ru

ORCID ID: 0000-0001-5875-8912 


\title{
The non-profit sector during the spread of the new coronavirus infection: restrictions and mechanisms to overcome them
}

\author{
K. E. Kosygina ${ }^{1 凶}$ \\ ${ }^{1}$ Vologda Research Center of the Russian Academy of Sciences, 56a Gorky str., \\ 160014 Vologda, Russian Federation
}

Cite as: Kosygina, K. E. (2021) The non-profit sector during the spread of the new coronavirus infection: restrictions and mechanisms to overcome them. Proceedings of Voronezh State University. Series: Economics and Management. 2, 27-39. DOI: https://doi.org/10.17308/econ.2021.2/3461

Subject. The COVID-19 pandemic has been challenging for the healthcare system, people's daily lives, and organisations, which have faced new risks and restrictions affecting their stability and further development. The study examines the state of Russian non-profit sector organisations during the spread of the new coronavirus infection.

Objectives. The article provides a description of restrictions for the development of non-profit sector organisations and various mechanisms to overcome them in the context of numerous restrictions introduced as a result of the spread of the new coronavirus infection.

Materials and methods. The information base for the study included statistical data, analytical and reporting documents of non-governmental and governmental institutions, and the results of the studies on the subject obtained by Russian and international researchers. The following methods were used: secondary analysis of sociological surveys; content analysis of official documents; systematisation and generalisation of the data.

Conclusions. The analysis showed that during the coronavirus pandemic Russian non-profit organisations as well as other economic entities faced a lot of challenges. The main restrictions for the sector were determined. They included financial and organisational restrictions. The measures of state support for non-profit organisations were framed into a unified organisational and economic mechanism and individual quantitative indicators were analysed: preferential loans, subsidies for activities to prevent the coronavirus infection, exemption from advance payments and insurance fees, the results of a special unscheduled contest of the Presidential Grants Fund for the Development of Civil Society. The analysis of quantitative indicators revealed that there is a demand for governmental anti-crisis measures among non-profit sector organisations. It was found that together with governmental measures aimed at overcoming the difficulties associated with the restrictive measures, a private organisational and economic mechanism was established to support non-profit organisations at the expense of business resources, which was studied by the authors based on the example of charitable funds. In conclusion, it was noted that the COVID-19 pandemic has enhanced the development of inter-sector cooperation aimed to solve common problems. Reliance on consolidation and partnership in difficult economic conditions will allow non-profit organisations to expand and select the most appropriate ways to support their activities.

Key words: restrictions, non-profit sector, SONPOs, pandemic, COVID-19, state support.

\section{Source of Financing}

The study was carried out with the financial support of the Russian Foundation for Basic Research within the framework of project 19-011$00724 \mathrm{~A}$ «Barriers to civil participation and mechanisms for overcoming them at the regional level».

\section{References}

1. Casey, J. (2015) The Nonprofit World - Civil Society and the Rise of the Nonprofit Sector. Boulder and London, Kumarian Press.

\section{Conflict of Interest}

The author declares the absence of obvious and potential conflicts of interest related to the publication of this article.

2. Corsini, L. \& Moultrie, J. (2021) Local and distributed manufacturing during the COVID-19 pandemic: Is a crisis a window of opportunity for sustainable development in the Global South? Strate- 
Некоммерческий сектор в период распространения новой коронавирусной инфекции...

gic Design Research Journal. 14, 1, 224-235. DOI: 10.4013 / sdrj.2021.141.19

3. Donthu, N. \& Gustafsson, A. (2020) Effects of COVID-19 on business and research. Journal of Business Research. 117, 284-289

4. Goodell, J., Goyal, A. \& Hasan, I. (2020) Comparing financial transparency between for-profit and nonprofit suppliers of public goods: Evidence from microfinance. Journal of International Financial Markets, Institutions \& Money. 64, 101-146.

5. Salamon, L., Anheier, H., List, R., Toepler, S. \& Sokolowski, S. (1999) Global civil society. Baltimore: Johns Hopkins University, Center for Civil Society Studies.

6. Willems, J., Boenigk, S. \& Jegers, M. (2014) Seven trade-offs in measuring nonprofit performance and effectiveness. Voluntas. 25(6), 1648-1670.

7. Anufrieva, E. M. (2020) Features of the provision of state aid to small and medium-sized businesses from the affected sectors of the economy in connection with the COVID-19 pandemic. Bulletin of the Penza State University. 4 (32), 31-34. (In Russian).

8. Artamonova, A. S. (2019) The role of non-profit organizations in the social sphere of the region (on the example of health care). Bulletin of the Samara State University of Economics. 11 (181), 24-73. (In Russian).

9. Zemtsov, S. P. \& Tsareva, Yu. V. (2020) Trends in the development of the sector of small and medium-sized enterprises in the context of a pandemic and crisis. Economic development of Russia. 5, 71-82. (In Russian).

10. Kamdina, L. V. (2020) Assessment of the impact of the COVID-19 pandemic on the quality of life of the population. Bulletin of the Chelyabinsk State University. 11 (445), 224-230. (In Russian).

11. Korneeva, I. E. (2016) Fundraising in Russian non-profit organizations: the results of empirical research. Monitoring of public opinion: Economic and social changes. 4, 48-66. (In Russian).
12. Kosygina, K. E. (2020) Intersectoral interaction: types of relations and development trends in modern Russian society. Problems of territory's development. 6 (110), 50-66. DOI: 10.15838 / ptd.2020.6.110.4 1. (In Russian).

13. Kremin, A. E. (2019) Management of the region's economy on the basis of small business development. Vologda, VolRC RAS. (In Russian).

14. Kulkova, V. Yu. (2020) Non-profit sector and state support of non-profit organizations in the service sector in the Russian Federation during the crisis of 2020. Public administration. 80, 5-21. (In Russian).

15. Osipov G.V. et al. (eds.) (2020) Russian society and state in a pandemic: socio-political situation and demographic development of the Russian Federation in 2020. Moscow, ITD «Perspective». (In Russian).

16. Suslova, S. V. (2015) The contribution of Russian non-profit organizations to the national economy. Finance and business. 1, 75-87. (In Russian).

17. Ukhanova, Yu. V. (2019) Civic participation in Russian regions: a comparative analysis. Territorial development issues. 5. DOI: 10.15838 / tdi.2019.5.50.6 (In Russian).

18. Tskhurbaeva, F. Kh. \& Farnieva, I. T. (2009) Organizational and economic mechanism of management of agricultural enterprises. Terra Economicus. 7, 151-154. (In Russian).

19. Shabunova, A. A. (2020) Health and self-preservation behavior of the population in the context of COVID-19. Social space. 3, URL: http://socialarea-journal.ru/article/28613 (In Russian).

20. Shmatova, Yu. (2020) E. Impact of COVID-19 on the mental health of the population (as an indicator of human potential): the experience of foreign studies. Problems of territory's development. 4 (108), 88-108. DOI: 10.15838 / ptd.2020.4.108.6 (In Russian).
Ksenia E. Kosygina, Researcher, Laboratory for Research of Social Processes and Efficiency of Public Administration, Department for Research of the Level and Lifestyle of the Population, Federal State Budgetary Institution of Sciences, Vologda, Russian Federation

E-mail: sene4ka.87@mail.ru

ORCID ID: 0000-0001-5875-8912
Received 12.05.2021

Accepted 17.06.2021 